\title{
Cost-minimization analysis of generic equivalents (bortezomib, decitabine and capecitabine) in comparison to the originator brand medicines in Colombia
}

\author{
Shyam Akku, MD; Amit Garg, MD; Suhas Khandarkar, MPharm
}

\begin{abstract}
Introduction: Majority of the Colombian population has become health insured leading to improved healthcare access in the country. Healthcare expenses have risen drastically, and cancer is responsible for the major disease burden. An option to reduce cost burden is to replace the use of originator drug products with generic formulations which are considered to be bioequivalent to the originator drugs and cost much less.

We conducted a cost-minimization study for Colombia to assess the savings that could be achieved with the use of generic formulations of three anticancer drugs, namely bortezomib, decitabine and capecitabine as compared to their originator products.

Methods: We compared the prices of originator and Dr Reddy's Laboratories Ltd generic equivalents of bortezomib, decitabine and capecitabine in Colombia for the year 2015. Prices of originator drugs were obtained from SISMED (Sistema de información de Precios de Medicamentos - Drug Price Information System), the prices of generic drugs were provided by Dr Reddy's Laboratories Ltd. Cost savings were estimated in value and percentages.

Results: The study showed the substantial savings of 63\% (US\$4.68 million) with bortezomib, 26\% (US\$0.29 million) with decitabine, and 46\% (US\$1.50 million) with capecitabine from Dr Reddy's Laboratories Ltd generics as compared to their originator branded medicines. Conclusion: Considering the high economic burden of cancer and high prices of originator anticancer drugs, our study highlights the need to replace the originator branded medicines with the generics. This will not only improve the patient access to medications but also be beneficial for the insurance payers in Colombia, thereby improving the overall healthcare system in the country.
\end{abstract}

Keywords: Anticancer drugs, cost-minimization, generics, pharmacoeconomics

\section{Introduction}

Colombia is an upper-middle income country with over 48 million people, as reported by the World Health Organization (WHO) in the year $2015[1,2]$. Over the past few years, Colombia has undergone various demographic and epidemiological changes viz. fall in total fertility rate from 3.24 children per woman in 1985 to 2.3 in 2013 while life expectancy has increased by four years over the period of 2000 to 2012 ; mortality rates have also declined from 1990 to 2012, e.g. under-five mortality rate: 35 vs 17 per 1,000 live births, maternal mortality ratio: 100 vs 83 per 100,000 live births $[2,3]$. Overall, healthcare expenditure has increased drastically in Colombia. According to WHO, around US\$962 per capita were spent on health expenditure in 2014 which accounted for $7.2 \%$ of gross domestic product (GDP) in the country $[1,3]$.

Non-communicable diseases account for $71 \%$ of total deaths in Colombia, and cancers constitute $17 \%$ of the total deaths [4]. Out of all the cancers, breast, stomach and colorectal cancer are three of the five most prevalent forms in Colombia accounting for $7 \%, 13.1 \%$ and $8.5 \%$ of total cancer mortality, respectively. Besides these, blood/bone marrow cancers (9.9\%) are also responsible for high burden of cancer-related deaths in the country (leukaemia 4.9\%, multiple myeloma 1.2\%, non-Hodgkin lymphoma 3.4\%, and Hodgkin lymphoma 0.4\%) [5].
However, launch prices for the anticancer drugs have substantially increased over time. Anticancer medicines rank first in terms of global spending in the pharmaceutical market (US\$91 billion in 2013). According to a recent study in the US, the average price of an anticancer drug is US\$65,900 in 2013, while the average survival benefit is 0.46 years [6]. Overall, the economic burden due to cancer cost US $\$ 290$ billion in 2010 with the greatest share of the medical costs (53\%). In fact, economic burden of cancer is estimated to be US\$8.3 trillion between the period 2011-2030 [7]. The economic burden of cancer per patient ranged from US\$0.54 in India to US\$4.32 in China, US\$7.92 in South America, US\$244 in Japan, and US\$460 in the US [8].

At present, majority of the Colombian population is covered under health insurance ( $85 \%$ in 2008 and 97\% in 2010) [3, 9]. This has secured the general population and increased the access to health care. However, health care in Colombia is in jeopardy as it faces financial constraints. One of the reasons attributed for this condition is high drug expenditure in the country. Colombia is believed to be one of the highest payers for drugs in the world due to extensive use of expensive originator drugs rather than generic molecules. Thus, there is a need to replace the originators with generic molecules in Colombia to bring down the overall healthcare economic expenditure [9].

\section{Author for correspondence: Shyam Akku, MD, Manager - Global Medical Affairs, Dr Reddy's Laboratories Ltd, 8-2-337, Road No. 3, Banjara Hills,} Hyderabad - 500034 AP, India

Submitted: 19 October 2016; Revised: 18 November 2016; Accepted: 21 November 2016; Published online first: 28 November 2016 
A recent cost-minimization study conducted by Alexandra et al. (Essential Medicines and Pharmaceutical Policies, World Health Organization) across 17 countries showed that substantial savings can occur by switching the purchases from originator medicines to generics. These savings ranged from $11 \%$ for beclomethasone inhaler to $73 \%$ for ceftriaxone injection [10]. Keeping in mind the high cost of anticancer drugs, we conducted a pharmacoeconomic study to estimate the savings that could be achieved with the use of generic formulations of anticancer drugs - bortezomib, decitabine and capecitabine - in comparison to their originator brands in Colombia.

\section{Methods \\ Rationale}

Pharmacoeconomics identifies, measures and compares the costs of various drug therapies to the society and the healthcare system. It helps the clinicians, health-payers, and other decision-makers to assess the costs and outcomes of various treatment options via cost-minimization, cost-benefit, cost-effectiveness and costutility analyses [11-13]. The choice of the analysis depends upon the clinical situation to be evaluated and the question being asked. Cost-minimization analysis compares the costs of treatments having similar outcomes and aims at identifying the most economic option available. On the other hand, cost-benefit analysis compares the costs and benefits of treatments that have different outcomes and the outcome is measured in monetary value. Cost-effectiveness analysis compares the costs per standardized units of effectiveness for treatments that have different outcomes. Cost-utility analysis compares the costs per quality-adjusted life years for treatments that have different outcomes. Thus, of the different pharmacoeconomic methods, cost-minimization analysis is the one that compares the two interventions when the clinical outcomes of both are equivalent [12]. This means that if the two drugs are equivalent to each other in terms of clinical and humanistic outcomes, e.g. generics and originator molecules, this method can be viable in making a decision with respect to the cost of the drug in order to choose the economical one [11].

Literature evidence clearly shows that generic molecules are equivalent to the originator drugs in terms of outcomes. As per the US Food and Drug Administration (FDA), generic drugs are approved only when they are bioequivalent to the branded drugs, and have demonstrated similar quality and performance [14]. Several systematic reviews have shown that cardiovascular and neurological generics are as clinically effective as the branded drug products [15-17]. Therefore, we chose the cost-minimization study to compare the costs of generic and originator products of three anticancer drugs namely bortezomib, decitabine and capecitabine in Colombia. Our study is further supported by a recent cost-minimization study that was conducted across 17 countries to estimate the savings that could be achieved by switching the use from the originator to generic drugs [10].

\section{Study methods}

In our cost-minimization study, we compared the prices of originator and Dr Reddy's Laboratories Ltd (DRL) generic drugs of bortezomib, decitabine and capecitabine in Colombia. For originator products, price data was obtained from the SISMED (Sistema de información de Precios de Medicamentos Drug Price Information System), Colombia. SISMED is an information system that provides the necessary data to analyse and control the drug prices in Colombia, and thus, helps in the regulation of the pharmaceutical market in the country.

The mean unit price of originator drugs was calculated for the year 2015. On the other hand, prices of generic drugs were provided by DRL. To estimate the maximum cost savings that could be generated if the originator branded medicines consumed were purchased at the price of generics, mean prices of originator brands and the price of generics were applied to the volume of originator branded medicines consumed. All the prices were calculated in US dollars to avoid any fluctuations in the currency value throughout the year 2015 .

\section{Results}

Our study showed high costs of the originator products as compared to the generic molecules for all the three anticancer drugs. The originator drug of bortezomib cost US\$7.48 million, decitabine US\$1.12 million and capecitabine US\$3.27 million. On the other hand, the generic bortezomib costed only US\$2.80 million, decitabine costed US\$0.83 million and capecitabine costed US $\$ 1.78$ million, see Figure 1.

In total, a saving of $63 \%$ was achieved with the use of the generic form of bortezomib, 26\% with decitabine, and $46 \%$ with capecitabine as compared to the originator drugs. Complete results for the three drugs are depicted in Table 1.

Figure 1: Total costs with the use of originator versus DRL generic of bortezomib, decitabine and capecitabine (estimated for the year 2015)

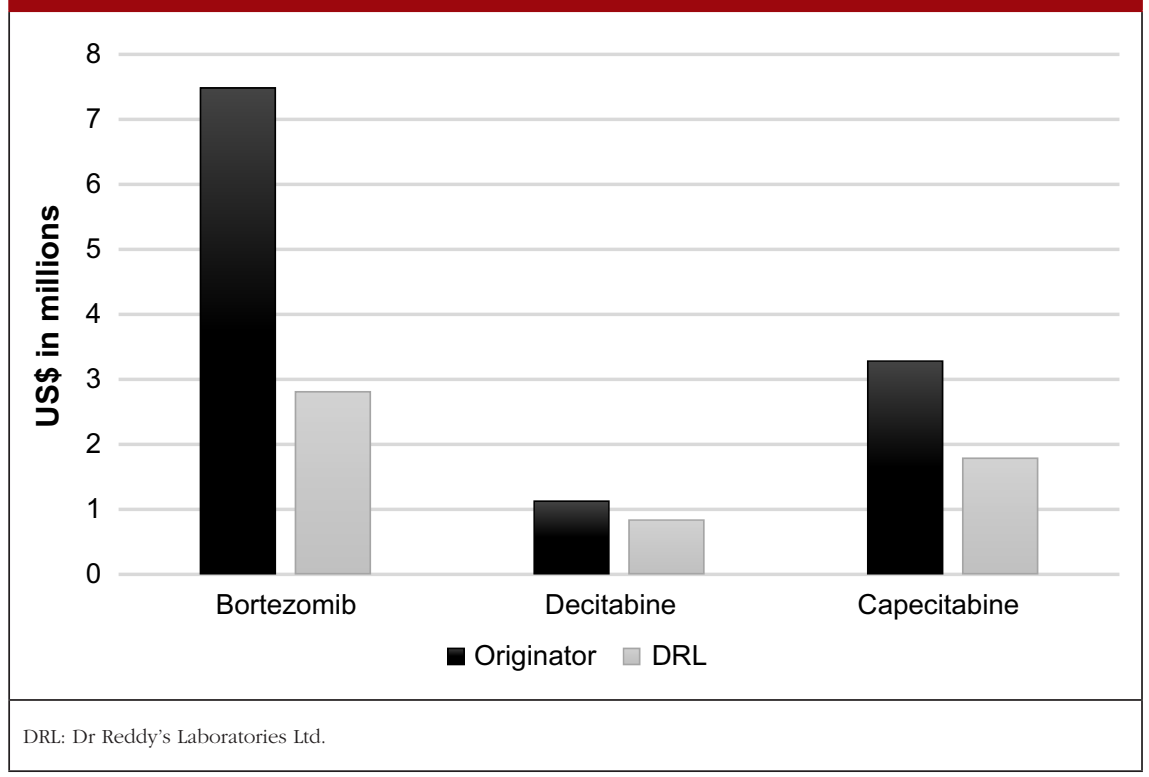




\begin{tabular}{|c|c|c|c|c|c|c|c|}
\hline \multirow{2}{*}{$\begin{array}{l}\text { Year } 2015 \\
\text { Drug }\end{array}$} & \multicolumn{3}{|c|}{ Originator } & \multicolumn{2}{|c|}{ DRL } & \multicolumn{2}{|c|}{ Savings } \\
\hline & Units & $\begin{array}{l}\text { Price } \\
\text { per unit }\end{array}$ & $\begin{array}{l}\text { Total } \\
\text { value }\end{array}$ & $\begin{array}{l}\text { Price } \\
\text { per unit }\end{array}$ & $\begin{array}{c}\text { Total } \\
\text { value }\end{array}$ & $\begin{array}{l}\text { Total } \\
\text { savings }\end{array}$ & $\begin{array}{l}\% \\
\text { savings }\end{array}$ \\
\hline Bortezomib & 9,586 & 781 & $7,482,740$ & 292 & $2,800,824$ & $4,681,917$ & 63 \\
\hline Decitabine & 1,053 & 1,059 & $1,115,049$ & 784 & 825,263 & 289,785 & 26 \\
\hline Capecitabine & 12,930 & 253 & $3,274,733$ & 137 & $1,777,821$ & $1,496,912$ & 46 \\
\hline
\end{tabular}

in Colombia. This can be very helpful for the insurance payers and bring a positive reform in the Colombian health care.

Competing interests: All authors are employees of Dr Reddy's Laboratories Ltd. Financial support was provided by Dr Reddy's Laboratories, Hydrabad, India.

Provenance and peer review: Not commissioned; externally peer reviewed.

\section{Discussion}

Our study is based on estimating the total savings that could be obtained by replacing the originator drugs of bortezomib, decitabine, and capecitabine with their DRL generic forms.

All these three drugs have gained a rational place in the treatment of various cancers and thus are commonly used. Bortezomib (as a single agent or in combination) is the preferred regimen for the treatment of multiple myeloma, both in the primary therapy as well as maintenance therapy, and used in relapsed patients. Also, it is approved as a second-line treatment for mantle cell lymphoma [18, 19]. Decitabine has been approved and used for the treatment of myelodysplastic syndrome and acute myeloid leukaemia [20, 21]. Capecitabine is used in the management of gastric, breast and colorectal cancer [22-25]. Moreover, all these three drugs have shown to confer cost savings in comparison to other anticancer drugs in their respective indications [26-35]. Therefore, using these drugs will not only help in the treatment of various cancers but can lead also to substantial cost savings.

Regarding the efficacy of generic medicines, it is well-proven that generics are bioequivalent to the originator drugs [14-17]. In fact, the Clinical Guidelines Committee of the American College of Physicians advises that clinicians should prescribe generic medicines in place of the expensive branded drugs. Generic medicines are not only associated with substantial cost savings, but also provide long-term adherence to the treatment [36].

Taking into account the field of oncology where medications are highly expensive, generics can play a very important role [37]. Generic imatinib is estimated to cost less than US\$1,000 per year within the next two years, while the average wholesale price of the branded imatinib is currently US\$145,750 [38]. An Indian study showed that anticancer generics cost $8.9 \%$ to $36 \%$ of the branded originator medications (irinotecan $8.9 \%$, paclitaxel $23 \%$, docetaxel $24 \%$, oxaliplatin $32 \%$ and gemcitabine $36 \%$ ), and around US\$843 million were estimated to be the potential yearly savings. All these studies highlight the need for generics substitution which can generate enormous cost savings and increase the access to cancer treatment globally [39]. Therefore, low- and middle-income countries like Colombia can improve the access to cancer medications by using the generic drugs.

\section{Conclusion}

This study highlights the substantial cost savings that could be achieved by replacing the originator drugs of bortezomib, decitabine, and capecitabine with the DRL generic formulations

\section{Authors}

Shyam Akku, MD

Amit Garg, MD

Suhas Khandarkar, MPharm

Dr Reddy's Laboratories Ltd, 8-2-337, Road No. 3, Banjara Hills, Hyderabad - 500034 AP, India

\section{References}

1. World Health Organization. Countries: Colombia. Geneva: WHO. 2016 [homepage on the Internet]. [cited 2016 Nov 18]. Available from: http://www. who.int/countries/col/en/

2. World Health Organization. Colombia: Country health profile. Geneva: WHO. 2016 [homepage on the Internet]. [cited 2016 Nov 18]. Available from: http:// www.who.int/countries/col/en/

3. Escobar ML, Giedion U, Giuffrida A, Glassman AL. Colombia: after a decade of health system reform. From few to many. Brookings Institution Press: Washington DC, USA; 2010. p. 1-6.

4. World Health Organization. Colombia: non-communicable diseases. Geneva: WHO. 2016 [homepage on the Internet]. [cited 2016 Nov 18]. Available from: http://www.who.int/countries/col/en/

5. World Health Organization. International Agency for Research on Cancer. Globocan 2012: estimated cancer incidence, mortality and prevalence worldwide in 2012. Population fact sheets: Colombia. France: IARC. 2016 [homepage on the Internet]. [cited 2016 Nov 18]. Available from: http://globocan. iarc.fr/Pages/fact_sheets_population.aspx

6. Howard DH, Bach PB, Berndt ER, Conti RM. Pricing in the market for anticancer drugs. J Econ Perspect. 2015;29(1):139-62.

7. Bloom DE, Cafiero ET, Jané-Llopis E, Abrahams-Gessel S, Bloom LR, Fathima S, et al. The global economic burden of non-communicable diseases. Geneva: World Economic Forum. 2011 [cited 2016 Nov 18]. Available from: http://www3.weforum.org/docs/WEF_Harvard_HE_GlobalEconomicBurdenNonCommunicableDiseases_2011.pdf

8. Lopes Gde L Jr, de Souza JA, Barrios C. Access to cancer medications in low- and middle-income countries. Nat Rev Clin Oncol. 2013;10(6):314-22.

9. Webster PC. Health in Colombia: a system in crisis. CMAJ. 2012;184(6): E289-90.

10. Cameron A, Mantel-Teeuwisse AK, Leufkens HG, Laing RO. Switching from originator brand medicines to generic equivalents in selected developing countries: how much could be saved? Value Health. 2012;15(5):664-73.

11. Rascati KL. Essentials of pharmacoeconomics. 2nd ed. Lippincott Williams \& Wilkins; 2014

12. Arenas-Guzman R, Tosti A, Hay R, Haneke E. National Institute for Clinical Excellence. Pharmacoeconomics - an aid to better decision-making. J Eur Acad Dermatol Venereol. 2005;19 (Suppl 1):34-9. 
13. Ambrosioni E, Borghi C. Pharmacoeconomic and cost-benefit aspects. Manual of hypertension of the European Society of Hypertension. Boca Raton, FL, USA: CRC Press; 2014. p. 316-20.

14. U.S. Food and Drug Administration. Facts about generic drugs [homepage on the Internet]. [cited 2016 Nov 18]. Available from: http://www.fda.gov/Drugs/ ResourcesForYou/Consumers/BuyingUsingMedicineSafely/UnderstandingGenericDrugs/ucm167991.htm\#_ftn1

15. Manzoli L, Flacco ME, Boccia S, D'Andrea E, Panic N, Marzuillo C, et al. Generic versus brand-name drugs used in cardiovascular diseases. Eur J Epidemiol. 2016;31(4):351-68.

16. Kesselheim AS, Stedman MR, Bubrick EJ, Gagne JJ, Misono AS, Lee JL, et al. Seizure outcomes following the use of generic versus brand-name antiepileptic drugs: a systematic review and meta-analysis. Drugs. 2010;70(5):605-21.

17. Dentali F, Donadini MP, Clark N, Crowther MA, Garcia D, Hylek E, et al. Warfarin Associated Research Projects and Other Endeavors (WARPED) Consortium. Brand name versus generic warfarin: a systematic review of the literature. Pharmacotherapy. 2011;31(4):386-93.

18. Anderson KC, Alsina M, Atanackovic D, Biermann JS, Chandler JC, Costello C, et al. NCCN guidelines insights: multiple myeloma, version 3.2016. J Natl Compr Canc Netw. 2016 Apr;14(4):389-400.

19. National Comprehensive Cancer Network. NCCN clinical practice guidelines in oncology (NCCN guidelines). Non-Hodgkin's lymphomas. Version 4.2014 [homepage on the Internet]. [cited 2016 Nov 18]. Available from: https://www. nccn.org/about/nhl.pdf

20. National Comprehensive Cancer Network. NCCN clinical practice guidelines in oncology (NCCN guidelines). Myelodysplastic syndromes. Version 2.2014 [homepage on the Internet]. [cited 2016 Nov 18]. Available from: http:// williams.medicine.wisc.edu/mds.pdf

21. National Comprehensive Cancer Network. NCCN clinical practice guidelines in oncology (NCCN guidelines). Acute myeloid leukemia. Version 2.2014 [homepage on the Internet]. [cited 2016 Nov 18]. Available from: http:// williams.medicine.wisc.edu/aml.pdf

22. National Comprehensive Cancer Network. NCCN Guidelines for patients. Colon cancer. Version 1.2016 [homepage on the Internet]. [cited 2016 Nov 18] Available from: https://www.nccn.org/patients/guidelines/colon/files/assets/ common/downloads/files/colon.pdf

23. National Comprehensive Cancer Network. NCCN clinical practice guidelines in oncology (NCCN guidelines). Rectal cancer. Version 2.2015 [homepage on the Internet]. [cited 2016 Nov 18]. Available from: https://www.tri-kobe.org/ nccn/guideline/colorectal/english/rectal.pdf

24. National Comprehensive Cancer Network. NCCN clinical practice guidelines in oncology (NCCN guidelines). Breast cancer. Version 1.2015 [homepage on the Internet]. [cited 2016 Nov 18]. Available from: http://www. cjcpt.org/files/2015/03-06/2015-NCCN/2015\%20NCCN\%20\%E4\%B9\%B3\% E8\%85\%BA\%E7\%99\%8C-V1.pdf

25. Ajani JA, Bentrem DJ, Besh S, D’Amico TA, Das P, Denlinger C, et al. Gastric cancer, Version 2.2013: featured updates to the NCCN Guidelines. J Natl Compr Canc Netw. 2013;11(5):531-46.
26. Hornberger J, Rickert J, Dhawan R, Liwing J, Aschan J, Löthgren M. The cost-effectiveness of bortezomib in relapsed/refractory multiple myeloma: Swedish perspective. Eur J Haematol. 2010;85(6):484-91.

27. Lancaster S. Bortezomib: the evidence of its clinical impact in multiple myeloma. Core Evid. 2006;1(4):265-77.

28. LeBlanc R, Hollmann S, Tay J. Canadian cost analysis comparing maintenance therapy with bortezomib versus lenalidomide for patients with multiple myeloma post autologous stem cell transplant. J Popul Ther Clin Pharmacol. 2016;23(1):e103-13

29. Garrison LP Jr, Wang ST, Huang H, Ba-Mancini A, Shi H, Chen K, et al. The cost-effectiveness of initial treatment of multiple myeloma in the U.S. with bortezomib plus melphalan and prednisone versus thalidomide plus melphalan and prednisone or lenalidomide plus melphalan and prednisone with continuous lenalidomide maintenance treatment. Oncologist. 2013;18(1):27-36.

30. Wiles S, Kabalan M, Sharma R, Shatzel J, Pang J, Yi D, et al. Decitabine is more cost effective than standard conventional induction therapy in elderly acute myeloid leukemia patients. Blood. 2013;122(21):2699.

31. Pan F, Peng S, Fleurence R, Linnehan JE, Knopf K, Kim E. Economic analysis of decitabine versus best supportive care in the treatment of intermediate- and high-risk myelodysplastic syndromes from a US payer perspective. Clin Ther. 2010;32(14):2444-56.

32. Ho MY, Chang AY, Ruan JY, Cheung WY. Population-based cost-minimization analysis of CAPOX versus modified FOLFOX6 in the adjuvant treatment of stage III colon cancer. Clin Colorectal Cancer. 2016;15(2):158-63.

33. Lin JK, Tan EC, Yang MC. Comparing the effectiveness of capecitabine versus 5-fluorouracil/leucovorin therapy for elderly Taiwanese stage III colorectal cancer patients based on quality-of-life measures (QLQ-C30 and QLQ-CR38) and a new cost assessment tool. Health Qual Life Outcomes. 2015;13:61.

34. Tse VC, Ng WT, Lee V, Lee AW, Chua DT, Chau J, et al. Cost-analysis of XELOX and FOLFOX 4 for treatment of colorectal cancer to assist decisionmaking on reimbursement. BMC Cancer. 2011;11:288.

35. Perrocheau G, Bennouna J, Ducreux M, Hebbar M, Ychou M, Lledo G, et al. Cost-minimisation analysis in first-line treatment of metastatic colorectal cancer in France: XELOX versus FOLFOX-6. Oncology. 2010;79(3-4):174-80.

36. Choudhry NK, Denberg TD, Qaseem A. Clinical Guidelines Committee of American College of Physicians. Improving adherence to therapy and clinical outcomes while containing costs: opportunities from the greater use of generic medications: best practice advice from the Clinical Guidelines Committee of the American College of Physicians. Ann Intern Med. 2016;164(1):41-9.

37. Renner L, Nkansah FA, Dodoo AN. The role of generic medicines and biosimilars in oncology in low-income countries. Ann Oncol. 2013;24 (Suppl 5):v29-32.

38. Gorkin L, Kantarjian H. Targeted therapy: generic imatinib - impact on frontline and salvage therapy for CML. Nat Rev Clin Oncol. 2016;13(5):270-2.

39. Lopes Gde L. Cost comparison and economic implications of commonly used originator and generic chemotherapy drugs in India. Ann Oncol. 2013;24 (Suppl 5):v13-6.

DOI: 10.5639/gabij.2016.0504.042

Copyright $\odot 2016$ Pro Pharma Communications International 